\title{
The Danish Centre for Strategic Research in Type 2 Diabetes (DD2) study: implementation of a nationwide patient enrollment system
}

This article was published in the following Dove Press journal:

Clinical Epidemiology

17 September 2012

Number of times this article has been viewed

\author{
Jens Steen Nielsen' \\ Reimar W Thomsen ${ }^{2}$ \\ Charlotte Steffensen ${ }^{2}$ \\ Jens S Christiansen ${ }^{3}$ \\ 'Department of Endocrinology M, \\ Odense University Hospital, Odense, \\ ${ }^{2}$ Department of Clinical Epidemiology, \\ ${ }^{3}$ Department of Endocrinology, Aarhus \\ University Hospital, Aarhus, Denmark
}

Correspondence: Jens Steen Nielsen DD2, Diabetes Research Centre, Department of Endocrinology M, Odense University Hospital, Kloevervaenget 10,

3rd floor, 5000 Odense C, Denmark

Tel +45 2I 609032

Fax +45 $66 \quad 125643$

Email jens.steen.nielsen@ouh.

regionsyddanmark.dk

\begin{abstract}
This paper aims to describe the patient enrollment system and implementation strategy for the new nationwide Danish Centre for Strategic Research in Type 2 Diabetes (DD2) project. The paper will also describe the design, current content, and pilot testing of the DD2 registration form. The challenge of the DD2 project was to construct a registration system functioning in the entire Danish health care system, where new type 2 diabetes patients are initially met, and with the capacity to enroll 200 newly diagnosed diabetes patients per week nationwide. This requires a fast and simple registration that is part of everyday clinical practice in hospital outpatient clinics and general practitioner (GP) clinics. The enrollment system is thus built on a tested, rational design where patients need only one visit and only specific limited data about physical activity, anthropometric measures, and family history of diabetes are collected during a brief patient interview. Later, supplemental data will be extracted by computerized linkage with existing databases. The feasibility of this strategy was verified in a pilot study. For maximum flexibility, three different ways to fill in the DD2 registration form were provided and an interactive webpage was constructed. The DD2 project also involves collection of blood and urine samples from each diabetes patient, to be stored in a biobank. Clinicians may obtain the samples themselves or refer patients to the nearest clinical biochemical department. GPs have the additional option of referring patients to the nearest hospital outpatient diabetes clinic to obtain interview data, clinical data, and samples. At present, the enrollment system is in use at 17 hospital outpatient diabetes clinics and 45 GP clinics nationwide, together enrolling 40 new type 2 diabetes patients per week in the DD2 project. A total of 990 patients have now been enrolled and the DD2 is ready to expand nationwide.
\end{abstract}

Keywords: DD2, type 2 diabetes, logistics, implementation, data registration, health information technology

\section{Introduction}

The new nationwide Danish Centre for Strategic Research in Type 2 Diabetes (DD2) project started in 2010. The DD2 project is designed to be one of the world's largest prospective diabetes research projects. For the first time, a nationwide type 2 diabetes research project of this kind is being conducted in Denmark. When fully implemented, the goal of the DD2 project is to enroll 10,000 patients annually in a database with a corresponding biobank; this corresponds to approximately half of all newly diagnosed type 2 diabetes patients in Denmark each year. The aim of this paper is to describe the initial considerations behind, and the final strategy and logistics for, the nationwide patient enrollment system in the DD2 project, including a description of the design, current content, and pilot testing of the DD2 registration form. The aim is also to provide 
an up-to-date status of the enrollment at the beginning of 2012 and describe strategies to facilitate participation in the DD2 project and reach future goals.

\section{Initial considerations about data collection in the DD2 project}

The main idea behind the DD2 project is to create a prospective, large, nationwide population-based cohort of newly diagnosed type 2 diabetes patients, with collection of matching interview data and biological samples for a biobank at baseline. ${ }^{1}$ Subsequently, the computerized DD2 data will be linked to other population-based medical databases; this provides access to important supplementary individual patient data. In Denmark this is possible because every resident has a unique personal identification called the civil registration number, which is used when storing data in many population-based databases and which makes exact data linkage between different medical databases possible. ${ }^{2}$ Thus, the DD2 cohort of 50,000 newly diagnosed type 2 diabetes patients can be followed over a long time for a variety of health outcomes through the extensive network of the population-based Danish medical databases. ${ }^{3}$ Moreover, the cohort may serve as a platform and project database for randomized clinical intervention trials, such as investigating effects of physical training, testing new antidiabetic drugs, or testing individualized pharmacological treatment. ${ }^{3}$ Finally, the DNA biobank data may enable nested case-control studies: for example, on the effect of pharmacological treatment in subsets of patients with specific genetic risk profiles. ${ }^{1}$

In Denmark, patients with newly diagnosed type 2 diabetes are followed and treated either by their general practitioners (GPs; an estimated $80 \%$ ) or by hospital outpatient diabetes clinics (an estimated 20\%). ${ }^{4}$ Patients are most often diagnosed for the first time by their GP, but may also be diagnosed for the first time during hospital stay. They may then be followed and treated by their GP, or referred to diabetes outpatient specialist clinics at the public hospitals. The system of diabetes care is not static; there is a continuous flow of diabetic patients between primary care and the hospital outpatient clinics and vice versa. Thus, GPs and hospital outpatient specialists form the natural base for recruiting new diabetes patients for the DD2 project. ${ }^{4}$ However, in contrast with hospital diagnoses there is no comprehensive health care registry of GP diagnoses in Denmark to easily identify all newly GP-diagnosed type 2 diabetes patients. Also, the necessity to obtain primary interview data and biological samples at baseline for each patient makes active enrollment by physicians necessary.
To enroll 50,000 patients in DD2 the procedure for enrollment has to be fast and simple. Therefore, we decided to collect only relatively few interview data, which could not be extracted from existing data sources, in addition to blood and urine samples. For the planned DD2 intervention studies of physical exercise intervention, individualized treatment, and genetic predictors, data on certain habitual lifestyle factors, weight gain, aerobic capacity, and family history of type 2 diabetes were deemed important, as they cannot be retrieved elsewhere. Initially, one of the major concerns during DD2 patient registration was to ensure high data quality in terms of completeness and validity. Therefore, it was decided that data collection would take place during a short patient interview conducted by a nurse or a medical doctor.

A DD2 registration form was developed including important questions about aerobic capacity, weight, family history of type 2 diabetes, and selected lifestyle factors, which are not included in any of the Danish population based databases.

\section{The DD2 registration form: design and content}

Often clinical multicenter trials require an extensive amount of data to be registered and collected from each patient and participating site. However, registering DD2 patients use a unique civil registration number, rendering it possible to obtain most data from other databases ${ }^{4}$ and reducing most of the time-consuming and expensive primary data collection. Thus, patient enrollment can be made simple and fast, and can be implemented as part of everyday clinical practice. Several hospital outpatient clinics stated early in the process that patient registration must not exceed 20 minutes if registration is to be part of everyday clinical practice. Therefore, careful consideration was needed to decide the parameters to be registered. These parameters will be discussed in the following paragraphs.

A family history of type 2 diabetes is a strong predictor for the development of type 2 diabetes in the next generation, ${ }^{5}$ and is also valuable for identifying patients where genomic sequestration could be worthwhile. Family history of diabetes might be examined by establishing family trees using the Danish Civil Registration System, but coding of diabetes diagnoses in the other available health care registries is incomplete. Therefore, we decided to register family history in the DD2 project by asking the patient if he/she had any known relatives in the 1st, 2 nd, or 3 rd generation suffering from diagnosed type 2 diabetes (Figure 1). 


\begin{tabular}{|c|c|}
\hline \multicolumn{2}{|c|}{ Registration form: DD2 } \\
\hline \multicolumn{2}{|c|}{$\begin{array}{l}\text { The form must be completed in connection with enrollment in DD2. } \\
\text { Inclusion criteria: All newly diagnosed patients with type } 2 \text { diabetes mellitus. }\end{array}$} \\
\hline \multicolumn{2}{|l|}{ Date } \\
\hline The date for carrying out the DD2 examination: & Day__ _ Month__ _ Year_ _ \\
\hline \multicolumn{2}{|l|}{ Patient data } \\
\hline The patient's civil registration number: & Day___ Month___Year_ _ - XXXX \\
\hline \multicolumn{2}{|l|}{ First name(s): } \\
\hline \multicolumn{2}{|l|}{ Last name: } \\
\hline $\begin{array}{l}\text { Is the patient fasting? } \\
\text { Thus, meaning that the patient has had no food nor } \\
\text { blood glucose regulating medication since } 22 \text { h0o the } \\
\text { day prior to the } D D 2 \text { examination }\end{array}$ & $\begin{array}{l}\square \text { Yes } \\
\square \text { No }\end{array}$ \\
\hline Has a blood sample been drawn for the biobank? & $\begin{array}{l}\square \text { Yes } \\
\square \text { No }\end{array}$ \\
\hline Has a urine sample been delivered for the biobank? & $\square$ Yes \\
\hline \multicolumn{2}{|l|}{ HIP-TO-WAIST RATIO (HTR) } \\
\hline $\begin{array}{l}\text { Hip and waist circumferences, measured directly on } \\
\text { the skin: }\end{array}$ & $\begin{array}{l}\text { Hip circumference__ } \mathrm{cm} \text { (whole number) } \\
\text { Waist circumference___ } \mathrm{cm} \text { (whole number) } \\
\text { HTR is calculated automatically upon entry in the } \\
\text { KMS system when the patient's hip and waist } \\
\text { circumferences are indicated. }\end{array}$ \\
\hline \multicolumn{2}{|r|}{ 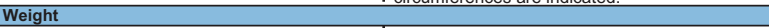 } \\
\hline Weight at the age of 20 : & — ${ }^{\mathrm{kg}}$ (whole number) aDon't know \\
\hline $\begin{array}{l}\text { Highest weight: } \\
\text { Does not include weight during a potential } \\
\text { pregnancy }\end{array}$ & _ $\mathrm{kg}$ (whole number) $\square$ Don't know \\
\hline
\end{tabular}

\begin{tabular}{|c|c|}
\hline ake & \\
\hline $\begin{array}{l}\text { The number of units per week: } \\
\text { This indicates the patient's usual consumption } \\
\text { during a normal week }\end{array}$ & $\begin{array}{l}\text { Q14/21 units/week or blow (woman/man) } \\
\square \text { More than 14/21 units/week (woman/man) }\end{array}$ \\
\hline Physical activity and exercise & \\
\hline $\begin{array}{l}\text { Number of days during a week where the patient is } \\
\text { physically active for at least } 30 \text { min per day: } \\
\text { This includes moderate or hard physical activity with } \\
\text { increased breathing, muscles exercise and use of } \\
\text { strength, eg, recreational sports or competitive } \\
\text { sports, heavy gardening, brisk walking, biking at } \\
\text { moderate or fast pace or physically strenuous work. } \\
\text { Both spare time and work activities are to be } \\
\text { included. }\end{array}$ & $\begin{array}{l}\square \text { No days } \\
\square 1 \text { day } \\
\square 2 \text { days } \\
\square 3 \text { days } \\
\square 4 \text { days } \\
\square 5 \text { days } \\
\square 6 \text { days } \\
\square \text { Everyday }\end{array}$ \\
\hline $\begin{array}{l}\text { Does the patient practice sport during his/her spare } \\
\text { time or does the patient participate regularly in other } \\
\text { physical activities? }\end{array}$ & $\begin{array}{l}\text { QYes } \\
\text { QNo }\end{array}$ \\
\hline $\begin{array}{l}\text { Physical activity during the patient's spare time } \\
\text { during the past year: }\end{array}$ & $\begin{array}{l}\text { Indicate by ticking off the box describing the } \\
\text { patient's physical activity the best: } \\
\text { QExercising strenuosly and practicing competitive } \\
\text { sport regularly and several time per week } \\
\text { QPracticing recreational sport or doing heavy } \\
\text { gardening or similar at least four hours per week } \\
\text { QWalking, biking or other light exercise at least four } \\
\text { times per week (also Sunday strolls, light gardening } \\
\text { and biking/walking to work should be included) } \\
\text { QReading, watching TV or other sedentary activity }\end{array}$ \\
\hline amily members with known type 2 diabetes & \\
\hline $\begin{array}{l}\text { Are there any persons with known type } 2 \text { diabetes } \\
\text { among the patient's immediate family? }\end{array}$ & $\begin{array}{l}\text { वYes } \\
\text { If yes, please indicate which family member(s) } \\
\square \text { Mother } \\
\square \text { Father } \\
\square \text { Maternal grandmother } \\
\square \text { Maternal grandfather } \\
\square \text { Paternal grandmother }\end{array}$ \\
\hline
\end{tabular}

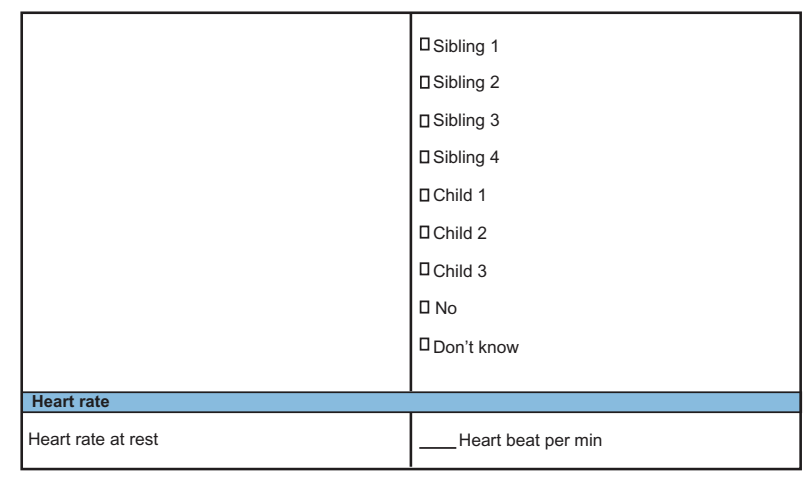

Figure I The DD2 registration form to be filled during the patient interview conducted during patient enrollment in the Danish Centre for Strategic Research in Type 2 Diabetes project.

Note: Variables are filled out successively from page one to page three during the DD2 registration interview.

Abbreviation: DD2, Danish Centre for Strategic Research in Type 2 Diabetes.

Aerobic capacity is best determined using direct measurements of maximal oxygen consumption during workout to exhaustion, but this is time-consuming and requires expensive equipment that is routinely available at only a few hospital outpatient clinics. An alternative way to estimate aerobic capacity is by using time-consuming validated questionnaires, which take approximately 20 minutes to complete. ${ }^{6}$ In the planned DD2 exercise intervention study, one aim is to motivate the least active patients to exercise more; ${ }^{3}$ knowing the patients' own perceptions of their physical activity levels prior to intervention is therefore important. We therefore decided to include three specific questions related to habitual physical activity levels during the patients' everyday lives in the DD2 registration form. These questions have all previously been used in other questionnaires for estimating physical activity (Figure 1).

Resting heart rate is a predictor of cardiovascular disease ${ }^{7}$ and decreases with increasing aerobic capacity. ${ }^{8}$ Aerobic capacity has been shown to predict whole-body insulin sensitivity. ${ }^{9}$ Resting heart rate may thus be a predictor of both type 2 diabetes and later cardiovascular complications, and a measurement of resting heart rate may supplement the 
more subjective questions about habitual aerobic activity. Therefore, we decided to measure resting heart rate at the end of the registration interview, after the patient has rested for 10 to 15 minutes in a chair.

The waist-to-hip ratio and the waist-to-height ratio are some of the best predictors of overall morbidity and mortality. ${ }^{10}$ These ratios are calculated from measurements of body height and the circumference of the hip and waist. Body height can be retrieved from supplemental data sources such as the Danish Diabetes Database for Adults (DDDA), ${ }^{4}$ but waist and hip circumferences have to be obtained from the patient. These measurements were thus added to the registration from.

Obese and overweight persons have a higher frequency of insulin resistance and a higher risk of cardiovascular problems. ${ }^{11}$ However, to our knowledge no study has ever investigated how a lifetime weight gain affects insulin resistance and risk of cardiovascular problems. Therefore, the highest body weight during the patient's lifetime and the body weight at the age of 20 were registered during each patient interview. Additionally, alcohol intake above or below the national guidelines from the Danish National Board of Health was recorded, as this important lifestyle parameter could not be retrieved elsewhere.

The final DD2 registration form is shown in Figure 1.

\section{Pilot test of the initial DD2 registration form}

Before implementing the DD2 registration form nationwide, a pilot study was conducted at the hospital outpatient clinics of two Danish university hospitals in Odense and Aarhus. First, patient registration in the DD2 was approved by the Danish National Committee on Biomedical Research Ethics (record number S-20100082) and the Danish Data Protection Agency (record number 2008-58-0035). The primary aim of the pilot study was to examine the applicability of, and any possible problems in filling out, the registration form in clinical practice. An additional aim was to test the setup and logistics of the biobank, as discussed in detail by Christensen et al. ${ }^{12}$

Prior to the pilot study, some concerns existed in the DD2 scientific steering committee that selected important data - ie, height, weight, and blood pressure - could not be retrieved validly from other data sources. Therefore, registration of height, weight, and blood pressure was initially added to the registration forms used at Odense University Hospital during the pilot test. Apart from this, the registration forms were identical to the final version shown in Figure 1, except that in the pilot study, only boxes for specific family members were present for the question about family history of type 2 diabetes - ie, "Yes", "No", and "Do not know" boxes were not present.

A total of 48 newly diagnosed type 2 diabetes patients were registered in the pilot study running from November 2010 to February 2011 at the hospital outpatient diabetes clinics at Aarhus (18 patients) and Odense university hospitals (30 patients). Data were recorded using electronic online forms (42 patients) and paper forms (6 patients), which are discussed later. Table 1 shows data collected during interviews of the 48 patients enrolled during the pilot study. The patients' median age was 63 years and ranged from 34 to 79 years. Of the 48 patients, 25 were male and 23 were female. Only $66 \%$ of the 48 patients were fasting when arriving for blood and urine sampling. The median maximal lifetime weight was $102 \mathrm{~kg}$ (range 70-150) for men and $90 \mathrm{~kg}$ (range 55-126) for women. This corresponded to a $22 \mathrm{~kg}$ weight gain for men and a $33 \mathrm{~kg}$ weight gain for women from their reported weight at the age of 20 years. The self-reported physical activity level was registered for all 48 patients: 16 patients reported that they were active for 30 minutes per day less than two times per week, 16 patients were active for 30 minutes per day three to four times per week, and 16 patients were active 30 minutes per day above five times per week. Thus, the selected questions seemed appropriate to divide patients into meaningful subgroups according to their habitual physical activity.

Diabetes history in specific family members was reported by $50 \%$ of the patients, but family member boxes were not checked for $43 \%$. It was not possible to conclude if missing data was due to there being no family history of diabetes. Therefore, a simple "Yes", No", and "Do not know" option was added to the final registration form (see Figure 1).

Following the pilot study, the civil registration number of the enrolled patients was used to link data with available diabetes data from the DDDA (this process is described in detail in Thomsen et $\mathrm{al}^{4}$ ). DDDA data could be obtained for almost all (17 of 18) of the DD2 patients from Aarhus University Hospital, but for only 3 out of 30 patients from Odense University Hospital. This later led to the recognition that data from newly diagnosed diabetes patients at Odense University Hospital and several other centers are not transferred to the DDDA until the diabetes patient has become "prevalent" at a later point of time (see discussion in Thomsen et $\mathrm{al}^{4}$ ). It also led to the conclusion that important data could in fact be retrieved from other supplementary data sources, as described in the paper by Thomsen et al. ${ }^{4}$ Thus, 
Table I Characteristics of the 48 patients with newly diagnosed type 2 diabetes enrolled in the Danish Centre for Strategic Research in Type 2 Diabetes (DD2) pilot study

\begin{tabular}{|c|c|}
\hline Variables & $\begin{array}{l}\text { Patients with } \\
\text { type } 2 \text { diabetes }\end{array}$ \\
\hline Participants in pilot test & $N=48(100 \%)$ \\
\hline Median age (quartiles), years & $63(55-66)$ \\
\hline Minimum-maximum age, years & $34-79$ \\
\hline \multicolumn{2}{|l|}{ Sex, n (\%) } \\
\hline Male & $25(52)$ \\
\hline Female & $23(48)$ \\
\hline \multicolumn{2}{|l|}{ Patient fasting at time of enrollment, ${ }^{a} \mathrm{n}(\%)$} \\
\hline Yes & $32(67)$ \\
\hline No & $16(34)$ \\
\hline $\begin{array}{l}\text { Resting heart rate beats per minute, median } \\
\text { (quartile) }\end{array}$ & $69(6 I-77)$ \\
\hline Waist-hip ratio in men, median (quartile) & $0.99(0.96-1.04)$ \\
\hline Waist-hip ratio in women, median (quartile) & $0.91(0.87-1.00)$ \\
\hline \multicolumn{2}{|l|}{ Weight gain in men } \\
\hline Weight at age 20 years, median (quartiles), $\mathrm{kg}$ & $75(66-82)$ \\
\hline Don't know weight at the age of 20 years, n (\%) & $3(12)$ \\
\hline Maximum lifetime weight, median (quartiles), $\mathrm{kg}$ & $102(90-127)$ \\
\hline Don't know maximum lifetime weight, $n$ (\%) & $0(0)$ \\
\hline $\begin{array}{l}\text { Weight gain since the age of } 20 \text { years, } \\
\text { median (quartiles), } \mathrm{kg} \\
\text { Weight gain in women }\end{array}$ & $22(13-32)$ \\
\hline Weight at the age of 20 years, median (quartiles), $\mathrm{kg}$ & $55(55-60)$ \\
\hline Don't know weight at the age of 20 years, n (\%) & $4(17)$ \\
\hline Maximum lifetime weight, median (quartiles), $\mathrm{kg}$ & $90(77-101)$ \\
\hline Don't know maximum lifetime weight, $n$ (\%) & $0(0)$ \\
\hline $\begin{array}{l}\text { Weight gain since the age of } 20 \text { years, median } \\
\text { (quartiles), kg }\end{array}$ & $33(20-4 I)$ \\
\hline \multicolumn{2}{|l|}{ Alcohol use, $n(\%)$} \\
\hline Maximum I4/2I drinks/week for women/men & $47(97)$ \\
\hline More than $|4 / 2|$ drinks/week for women/men & I (2) \\
\hline \multicolumn{2}{|l|}{$\begin{array}{l}\text { Days per week with } 30+\text { minutes of physical } \\
\text { activity }\end{array}$} \\
\hline 0 days & $6(13)$ \\
\hline I day & $4(8.3)$ \\
\hline 2 days & $4(8.3)$ \\
\hline 3 days & $7(15)$ \\
\hline 4 days & $5(10)$ \\
\hline 5 days & $6(13)$ \\
\hline 6 days & $2(4.2)$ \\
\hline 7 days & $14(29)$ \\
\hline \multicolumn{2}{|l|}{ Regular sports activities, n (\%) } \\
\hline Yes & $23(48)$ \\
\hline No & $25(52)$ \\
\hline \multicolumn{2}{|l|}{ Level of physical activity during the past year, n (\%) } \\
\hline $\begin{array}{l}\text { Hard physical training and competitive } \\
\text { sports several times a week }\end{array}$ & $0(0)$ \\
\hline $\begin{array}{l}\text { Leisure sports, heavy garden work or similar } \\
\text { at least } 4 \text { hours per week }\end{array}$ & $13(27)$ \\
\hline $\begin{array}{l}\text { Walking, cycling, or other light exercise } \\
\text { at least } 4 \text { hours per week }\end{array}$ & $28(58)$ \\
\hline $\begin{array}{l}\text { I read, watch television, or have other } \\
\text { sedentary activity }\end{array}$ & $6(12)$ \\
\hline Missing & I (2.1\%) \\
\hline
\end{tabular}

(Continued)
Table I (Continued)

\begin{tabular}{ll}
\hline Variables & $\begin{array}{l}\text { Patients with } \\
\text { type } \mathbf{2} \text { diabetes }\end{array}$ \\
\hline Family history of diabetes, $\mathrm{n}(\%)$ & \\
No & $24(50)$ \\
Don't know & $3(6.3)$ \\
Yes & $21(44)$ \\
Father & $6(25)$ \\
Mother & $7(29)$ \\
Father's mother & $5(2 \mathrm{I})$ \\
Father's father & $\mathrm{I}(4.2)$ \\
Mother's mother & $4(17)$ \\
Mother's father & $3(13)$ \\
Sibling & $6(25)$ \\
Mother's sister & $\mathrm{I}(4)$ \\
Not stated who & $\mathrm{I}(42)$ \\
\hline
\end{tabular}

it was finally decided not to register blood pressure, height, weight, and any other clinical data on the DD2 registration form as they could be found in other databases accessible to DD2.

\section{Challenges concerning data registration during patient enrollment}

The initial challenge of the DD2 project was to construct a registration system to work in the entire Danish health care system and with the capacity to enroll 200 newly diagnosed type 2 diabetes patients per week. The number of 200 patients per week corresponds to approximately half of all newly diagnosed type 2 diabetes patients in Denmark. ${ }^{13}$ To enroll such a large number of patients in everyday clinical work, the enrollment system needs to be flexible, simple, and fast. This will reduce costs and enable clinicians to incorporate the enrollment routines into everyday clinical work. One of the major concerns prior to initiating the $\mathrm{DD} 2$ project nationwide was thus to make patient enrollment available to both primary and secondary health care personnel.

Additionally, the enrollment must follow Danish rules and regulations. The ethical regulations require that patients volunteer to participate in scientific projects and that they receive detailed oral and written information and have time for deliberation prior to signing a written informed consent. To make this process simple and fast, free access to ethically approved patient information was published online at the DD2 webpage (http://www.dd2.nu) in three languages: Danish, Arabic, and Turkish. In addition, an ethical approval was obtained allowing local physicians or other health personnel to give patient information and conduct the registration after a short instruction from DD2. 
Registration of 50,000 patients using paper registration is costly and time-consuming. Therefore, an online system was required. However, local information technology (IT) systems vary between nearly every hospital, and in Danish GP clinics 12 different IT systems exist. This makes design of one single, fully implemented online registration system difficult. However, all Danish hospitals have access to a simple IT system called the clinical measurement system (KMS), which is used for reporting to nationwide clinical quality databases including the $\mathrm{DDDA}^{4}$ and is able to register the patient data required in DD2. Therefore, the DD2 registration form (Figure 1) was implemented in the KMS. Before being able to use the KMS, diabetes patients must be registered in the DDDA, however. Since DD2 is meant to enroll newly diagnosed type 2 diabetes patients, whereas the DDDA is meant to measure clinical quality in known prevalent type 2 diabetes patients, not all relevant new patients are initially registere in the DDDA. ${ }^{4}$ Additionally, the KMS is not available for GP clinics. Therefore, a more flexible and simple online data registration system was required.

A new online data registration system was developed as part of the DD2 webpage. Data quality was secured by allowing only validated civil registration numbers to be entered, and by allowing users to proceed through the stages of data registration only if all data fields were filled with plausible data values. The biggest problem with data entry via the webpage was that different hospitals and GP clinics used up to three different versions of Microsoft Windows (Microsoft, Redmond, WA) and five different Internet browsers, and often the versions were old. These programs all used different ways to visualize the program codes for the registration form and the required codes varied from version to version within the same program. To solve this, a program code was developed detecting both browser and operating system of the user prior to loading a specially designed template matching the specific program of the user. As backup, a paper version of the DD2 registration form was designed and made accessible for print online, but when using the paper version, data must still be entered online afterwards. All three registration forms were $100 \%$ visually identical.

Due to data safety regulations when working with civil registration numbers, a secure login is required for the health care personnel to fill out registration forms online. Either the DD2 webmaster or the Danish Clinical Registers (DCR) in charge of the DDDA and the $\mathrm{KMS}^{4}$ provide the login, depending on the system used. For simplicity, DD2 users are allowed to create individual passwords and may request an individual user name.
Analysis of data entry to the DD2 database for the first 856 patients registered in January 2012 shows that $97 \%$ of all data entry currently happens during the patient interview using the DD2 online system. Three percent used the paper version of the data form and conducted online data entry later, and none of the first 856 patients were registered via the KMS.

At present, the DD2 Internet system has more than 110 unique users from the primary and secondary care sector, who frequently $\log$ on to the system. However, the system is prepared to serve all 3,500 Danish GPs and 40 hospital outpatient diabetes clinics. These can become users automatically whenever required within seconds, and additional users can be created manually within minutes. To have the correct contact information on all participating hospital outpatient clinics and GPs, the health care personnel are prompted to type their contact information when logging in for the first time and again every 12 months. Thus, the unique Web-based DD2 system is ready to register patients from the entire health care system, can easily be expanded when required, and holds the updated contact information of all participating GPs and hospital outpatient clinics nationwide.

Besides being a platform for online data registration and providing necessary information to health care personnel, the DD2 Website holds other important information about the project. The initial idea was that the DD2 Website should become the main platform in Denmark for providing evidence-based knowledge about type 2 diabetes and its treatment, and the DD2 project. The objective is that patients, medical doctors, other health care providers, scientists, journalists, and politicians easily can find the newest and valid information about the DD2 project and type 2 diabetes when required. Patients can even sign up to participate or deregister from the DD2 project directly via the DD2 Website. All this is prepared and in use as part of the DD2 Website that has 800 new unique visitors every month and over 250 persons receiving DD2 newsletters four times a year.

\section{Description of the enrollment logistics at hospital outpatient diabetes clinics}

During the initial pilot study, the strategy to run patient information, registration, interview, and blood sampling at the same occasion was deemed appropriate for all hospital outpatient diabetes clinics, as shown in Figure 2 in the upper right side. However, when starting enrollment at 


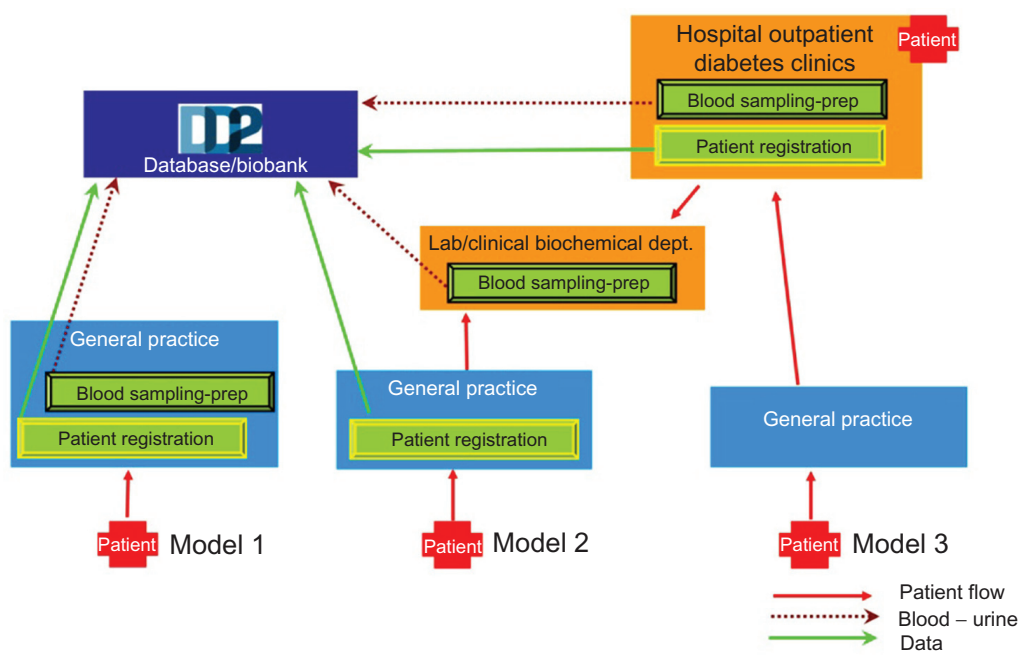

Figure 2 This figure shows how the Danish Centre for Strategic Research in Type 2 Diabetes (DD2) enrollment is arranged and how it can be conducted by both hospitals and general practitioners.

Notes: The enrollment consists of patient registration and blood sampling and preparation (-prep). For a detailed description see text. Red arrows indicate patient migration, green arrows indicate data transferred to the DD2 database, and dark red dots indicate blood and urine samples sent to the DD2 biobank.

different outpatient clinics, flexibility was immediately shown to be a key issue. Therefore, it was made possible to separate patient information and patient registration from the blood and urine sampling. This opened up the possibility for collaboration between different hospital departments and resulted in three different ways to enroll patients from hospital outpatient diabetes clinics (Figure 2). In brief, the three approaches are as follows: (1) A few large hospital outpatient diabetes clinics have employed research laboratory technicians or research nurses, who can make a complete patient enrollment including samples. This way of organizing the DD2 project is extremely effective; (2) Hospital outpatient diabetes clinics without research personnel can split up the enrollment into patient registration and blood and urine sample collection. Typically, a diabetes nurse will inform the patient, and conduct the online registration process, and then refer the patient to the local clinical biochemical department for blood and urine sampling. Typically, the biochemical department will be engaged to take and handle blood and urine samples immediately prior to or after the patient interview and clinical data registration; (3) Alternatively, the patient is referred to the clinical biochemical department to have blood and urine samples taken at a later occasion.

To facilitate cooperation between DD2 and the hospital outpatient diabetes clinics, the clinics are invited to participate in scientific projects. ${ }^{3}$ Together with a limited financial support offered by DD2 per enrolled patient, the objective is to facilitate open collaboration and a stable and constant patient enrollment from the hospital outpatient diabetes clinics.

At present (February 2012), 17 hospital outpatient diabetes clinics, located around the entire nation, continuously enroll patients in the DD2 project.

\section{Description of the enrollment logistics at GP clinics}

Approximately $80 \%$ of the newly diagnosed type 2 diabetes patients are followed and treated by their GPs. ${ }^{4}$ Therefore, DD2 needs a close collaboration with the Organization of General Practitioners in Denmark. To facilitate this, the enrollment system for GPs was developed in close collaboration with local and national parts of the Organization of General Practitioners in Denmark and the reimbursement negotiated with the national organization. Furthermore, a group of GP researchers is currently developing specific research project proposals of main interest and importance to the GP setting. The aim is to develop these and other local initiatives to facilitate a strong collaboration between GPs and DD2.

The GP clinics in Denmark differ much in size, laboratory facilities, number of employed personnel, and number of patients. In average, each clinic has 2.3 medical doctors, but this number varies between one and eight. Early after the pilot study, we realized that the heterogeneous structure of the GP clinics requires different setups for enrollment to succeed for all types of clinics. To develop these enrollment setups, delegates from the Organization of General Practitioners 
in Denmark and other representative GPs were asked for their opinion on structuring the patient enrollment. This collaboration resulted in three approaches for patient enrollment from GP clinics (Figure 2).

In approach one (Figure 2), the delivery of patient information, the completion of the registration form, and the collection of blood and urine samples are all performed at the GP's clinic. This approach is widely selected by large GP clinics and by rural clinics. Patients enrolled through approach one do not need to be in contact with the regional hospital outpatient diabetes clinic at all.

In approach two, the GP provides patient information and fills out the online registration form, but the blood and urine samples are collected at the nearest hospital clinical biochemical department. The patient is referred to the hospital clinical biochemical department through a wellestablished Internet-based referral system called WebReq (WebReq, Vejle, Denmark), This system is widely used by GPs to refer patients to routine blood and urine sampling at the hospital clinical biochemical departments. In the WebReq system, we have developed a special DD2 sample package, which is easy to use for GPs and just as easily received at any hospital clinical biochemical department nationwide. This approach is typically used in small urban clinics where a laboratory is located within short distance of the patients.

In approach three, patients are, after a short introduction to the DD2 project, referred to the nearest hospital outpatient diabetes clinic where registration, all interview data, clinical data, and blood and urine samples are obtained. The patient is referred to the hospital outpatient diabetes clinic via the usual web-based referral system from the GPs to the hospitals. Immediately after enrollment, the patient returns to the GP to continue normal type 2 diabetes treatment and follow-up. This approach is typically used by GP clinics, large or small, possessing no centrifuge, which is required for the handling of the blood samples. ${ }^{12}$

At present, patient enrollment from GPs is fully structured and organized in one of the five Danish regions, the Region of Southern Denmark. Here, 83 of approximately 300 GP clinics have signed up to start enrolling patients in the DD2 system, among them the largest GP clinics and key opinion leaders. Of the 83 clinics, $70 \%$ have chosen approach one, 25\% approach two, and 5\% approach three. The GPs are reimbursed depending on the approach chosen. The reimbursement is paid and administrated by the Region of Southern Denmark, using a national settlement system. ${ }^{4}$ At present, 44 of the 83 GP clinics participating have actually enrolled patients, and one large GP clinic in Farum, in the Capital Region of Denmark, has started enrolling patients.

The DD2 patient enrollment conducted from GP clinics as described above still needs to be structured and organized in the remaining four Danish regions. This has to be conducted in collaboration with the local GP organizations and each of the four regions. To complete this, negotiations are currently ongoing and the expectation is that the DD2 project will be implemented in at least two additional regions during 2012.

\section{Status of patient enrollment January 2012}

At present, the web-based online registration form is on average used to enroll 40 patients per week. Approximately $70 \%$ of these patients are enrolled from the 17 hospital outpatient diabetes clinics currently participating in the DD2 project (Figure 3). A few of these clinics have enrolled patients since late spring 2011, but most of them have started just recently. As seen in Figure 3, the hospital outpatient diabetes clinics are distributed all over Denmark.

Approximately $30 \%$ of the 40 patients enrolled per week are presently enrolled from the 44 actively participating GP clinics in the Region of Southern Denmark (Figure 4). Most of these GP clinics started enrolling patients in October 2011 and new clinics start enrolling patients weekly. We expect that the number of DD2 patients will increase substantially when the remaining GP clinics start enrolling patients, which we expect will happen within a short time. In addition, another 16 hospital outpatient diabetes clinics have agreed to participate in the DD2 project (Figure 3), of which four will start within a short time. Thus, we believe that patient enrollment will increase to above 50 patients per week during spring 2012. Estimations based on enrollment speed from the active hospital outpatient diabetes clinics and GP clinics indicate that the goal of enrolling 200 patients per week is within reach when the remaining 16 hospital outpatient diabetes clinics and the GPs from the remaining four Danish regions start enrolling patients in the DD2 project.

\section{Conclusion}

The challenge of the DD2 project was to construct a registration system functioning in the entire Danish health care system, ie, at both hospital outpatient clinics and GP clinics. The registration system was thus built on a tested, rational design where patients need only one visit, and only specific limited data are collected during a short patient interview, combined with data extracted from already existing databases. Based on initial considerations, an online registration form 


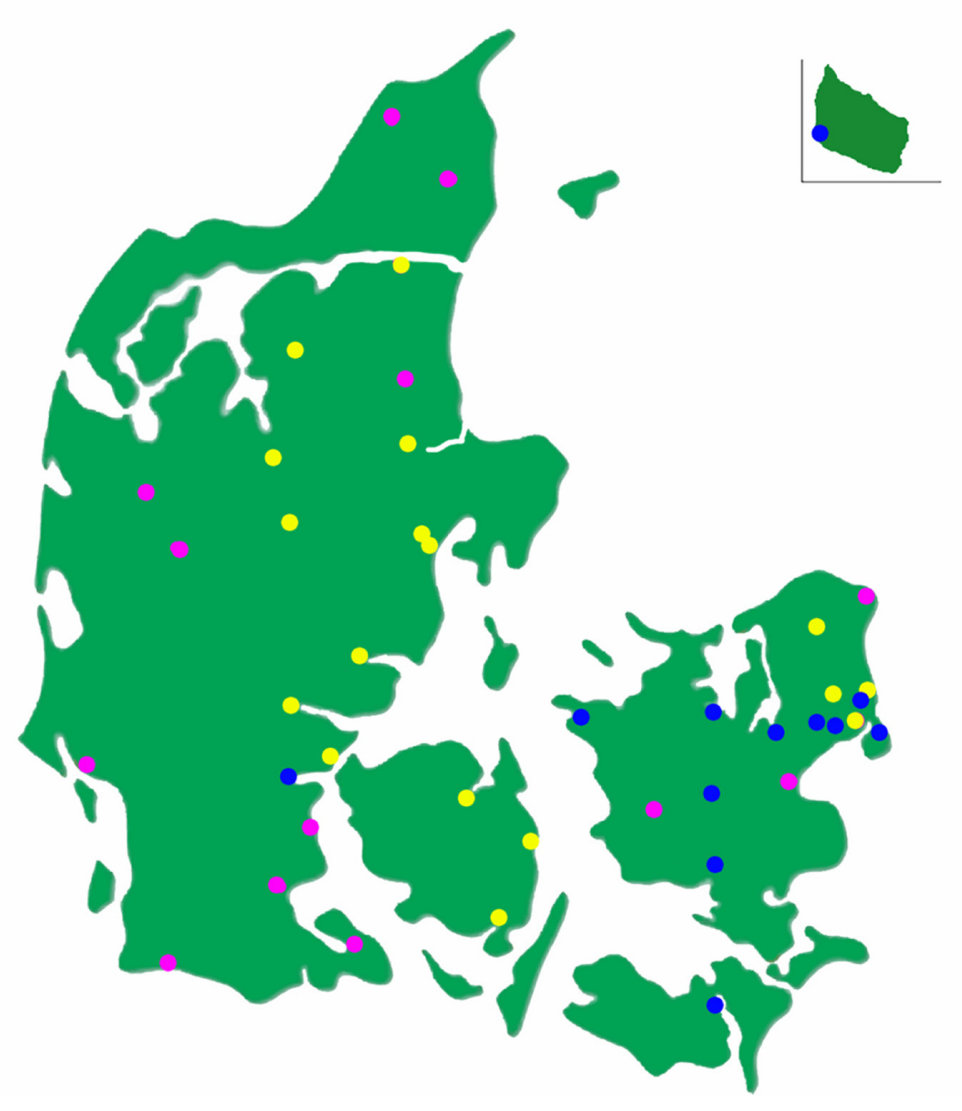

Figure 3 Map of Denmark showing the hospital outpatient diabetes clinics currently enrolling patients in the Danish Centre for Strategic Research in Type 2 Diabetes (DD2) project (the yellow dots), those that have agreed to start enrolling (purple dots), and those that have not yet been contracted officially by the DD2 (blue dots).

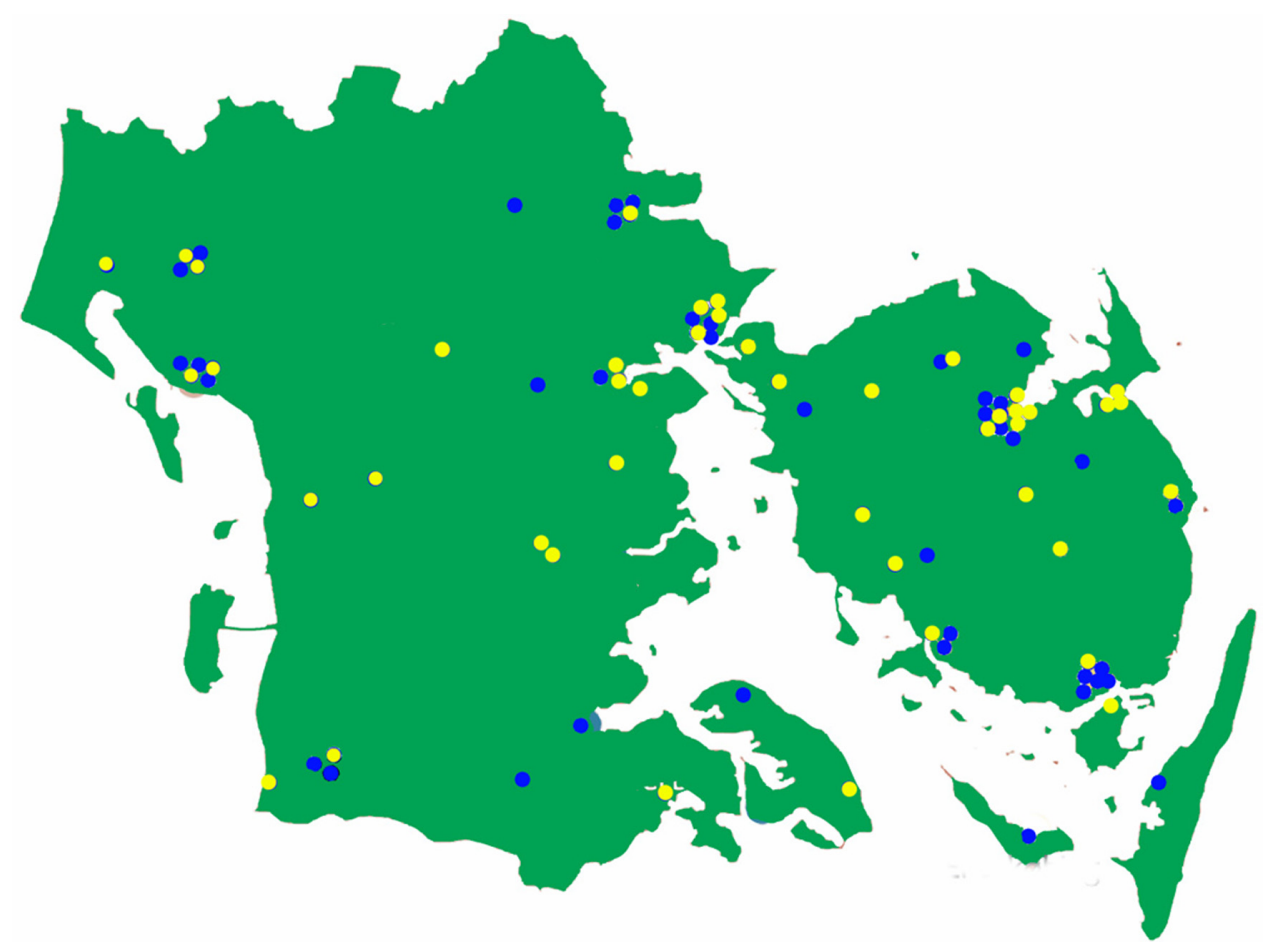

Figure 4 Map of the Region of Southern Denmark showing the location of the 84 general practitioners (blue dots) who have signed to start the Danish Centre for Strategic Research in Type 2 Diabetes (DD2) project. 
was developed, and the feasibility of this strategy, including the online registration form, were verified in a pilot study in order to create the optimal registration system based on the experiences from the pilot study. This nationwide patient enrollment system has thus made it possible to register at least 200 newly diagnosed type 2 diabetes patients per week in Denmark at both hospital outpatient diabetes clinics and GP clinics. At present, the enrollment system is in use at 17 hospital outpatient diabetes clinics and 44 GP clinics nationwide, and a total of 990 patients have now been enrolled in the DD2 project. Furthermore, close collaboration with all relevant health care providers, other relevant institutions, and political associations has been initiated. Thus, the platform for making the DD2 project a national and international success has been constructed.

\section{Acknowledgments}

DD2 is the acronym for 'The Danish Centre for Strategic Research in Type 2 Diabetes' supported by the Danish Agency for Science (grant no. 09-067009 and 09-075724). DD2 is also supported by The Danish Health and Medicines Authority, The Danish Diabetes Association and an unrestricted donation from Novo Nordisk A/S. The partners of the project are listed on the project website at www.DD2.nu.

\section{Disclosure}

The authors report no conflicts of interest in this work.

\section{References}

1. Steffensen S, et al. The Danish Centre for Strategic Research in type 2 Diabetes (DD2) Project: Rationale and planned nationwide studies of genetic predictors, physical exercise and individualised pharmacological treatment. Clin Epidemiol. 2012; In press.

2. Pedersen CB. The Danish Civil Registration System. Scand J Public Health. 2011;39(7 Suppl):22-25.

3. Beck-Nielsen H, Solomon PJ, Lauridsen J, et al. The Danish Centre for Strategic Research in Type 2 Diabetes: expected outcome from the DD2-project and two intervention studies. Clin Epidemiol. 2012; In press.
4. Thomsen RW, Friborg S, Nielsen JS, Schroll H, Johnsen SP. The Danish Centre for Strategic Research in Type 2 Diabetes (DD2): organization of diabetes care in Denmark and supplementary data sources for data collection among DD2 study participants. Clin Epidemiol. 2012; In press.

5. Valdez R. Detecting undiagnosed type 2 diabetes: family history as a risk factor and screening tool. J Diabetes Sci Technol. 2009;3(4): 722-726.

6. Taylor HL, Jacobs DR Jr, Schucker B, Knudsen J, Leon AS, Debacker G. A questionnaire for the assessment of leisure time physical activities. J Chronic Dis. 1978;31(12):741-755.

7. Reil JC, Custodis F, Swedberg K, et al. Heart rate reduction in cardiovascular disease and therapy. Clin Res Cardiol. 2011;100(1): $11-19$.

8. Rahnama N, Nouri R, Rahmaninia F, Damirchi A, Emami H. The effects of exercise training on maximum aerobic capacity, resting heart rate, blood pressure and anthropometric variables of postmenopausal women with breast cancer. $J$ Res Med Sci. 2010;15(2):78-83.

9. Bruce CR, Anderson MJ, Carey AL, et al. Muscle oxidative capacity is a better predictor of insulin sensitivity than lipid status. J Clin Endocrinol Metab. 2003;88(11):5444-5451.

10. Yang CY, Peng CY, Liu YC, Chen WZ, Chiou WK. Surface anthropometric indices in obesity-related metabolic diseases and cancers. Chang Gung Med J. 2011;34(1):1-22.

11. Reaven GM. Insulin resistance: the link between obesity and cardiovascular disease. Med Clin North Am. 2011;95(5):875-892.

12. Christensen H, Nielsen JS, Sørensen KM, Melbye M, Brandslund I. The new national Biobank of the Danish Center for Strategic Research in type 2 Diabetes (DD2). Clin Epidemiol. 2012; In press.

13. Carstensen B, Kristensen JK, Ottosen P, Borch-Johnsen K. The Danish National Diabetes Register: trends in incidence, prevalence and mortality. Diabetologia. 2008;51(12):2187-2196.
Clinical Epidemiology

\section{Publish your work in this journal}

Clinical Epidemiology is an international, peer-reviewed, open access journal focusing on disease and drug epidemiology, identification of risk factors and screening procedures to develop optimal preventative initiatives and programs. Specific topics include: diagnosis, prognosis, treatment, screening, prevention, risk factor modification, systematic

Submit your manuscript here: http://www.dovepress.com/clinical-epidemiology-journal

\section{Dovepress}

reviews, risk \& safety of medical interventions, epidemiology \& biostatical methods, evaluation of guidelines, translational medicine, health policies \& economic evaluations. The manuscript management system is completely online and includes a very quick and fair peer-review system, which is all easy to use. 